\title{
HEDENDAAGSE KOREAANSE LAKKUNST
}

De tentoonstelling Posities in de hedendaagse Koreaanse lakkunst geeft met een keur aan werken van gerenommeerde kunstenaars een goed beeld van de lakkunst van dit moment op het Koreaanse schiereiland. Diverse technieken die deel uitmaken van de rijke Koreaanse traditie worden door de actuele lakkunst in Korea weer opgepakt en opnieuw geïnterpreteerd. De werken die in de herfst/winter van 2015 in het Museum für Lackkunst in Münster worden gepresenteerd, zijn de artistieke neerslag van de eigen, onafhankelijke positie die de Koreaanse lakkunst na een bewogen 20e eeuw inneemt.

"Karakteristiek voor de tentoonstelling Posities in de hedendaagse Koreaanse lakkunst”, zo vertelt curator Patricia Frick, "zijn uiteenlopende facetten als diversiteit en continuïteit, maar ook innovatie en actualiteit, alsmede de moderne interpretatie van traditionele ambachtelijke technieken." Bij de selectie van de kunstenaars lette Frick erop dat zij teruggrijpen op traditionele technieken en veredelingsprincipes, maar daarbij wel een eigen weg bewandelen, los van de overgeleverde vormen en motieven van de Koreaanse lakkunst. Tot de traditionele procedés behoren de zogenoemde drooglaktechniek en het inleggen met parelmoer - beide komen voor in het oeuvre van de Koreaanse kunstenaars. Kenmerkend voor alle negen kunstenaars is bovendien dat zij na hun ambachtelijke scholing nog een hogeschool studie hebben voltooid en dat enkelen van hen studiejaren in een ander Aziatisch land hebben doorgebracht -veelal een bron van inspiratie die hun werk heeft bepaald.

Op de tentoonstelling in Münster zal van de volgende negen kunstenaars werk te zien zijn: Choe Young Keun, Chung Hae Cho, Chung Young Hwan, Jung Yong Ju, Kim Seol, Kim Sung Soo, Lee Hwa Jin, Lee Eun Hee en Moon Young Sic.

- Positionen der zeitgenössischen koreanischen Lackkunst

25 oktober 2015 - 7 februari 2016

Museum für Lackkunst - Münster

Windthorststraße 26, 48143 Münster, Duitsland 


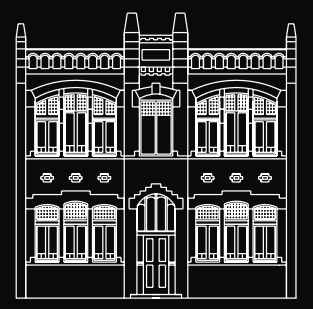

\section{ZeeuWs Veilinghuis Z E E L A N D A U C T I O N E R S}

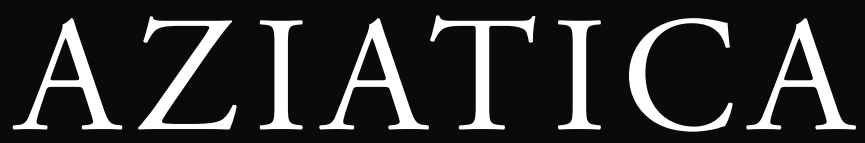

GEVRAAGD VOOR KOMENDE VEILING

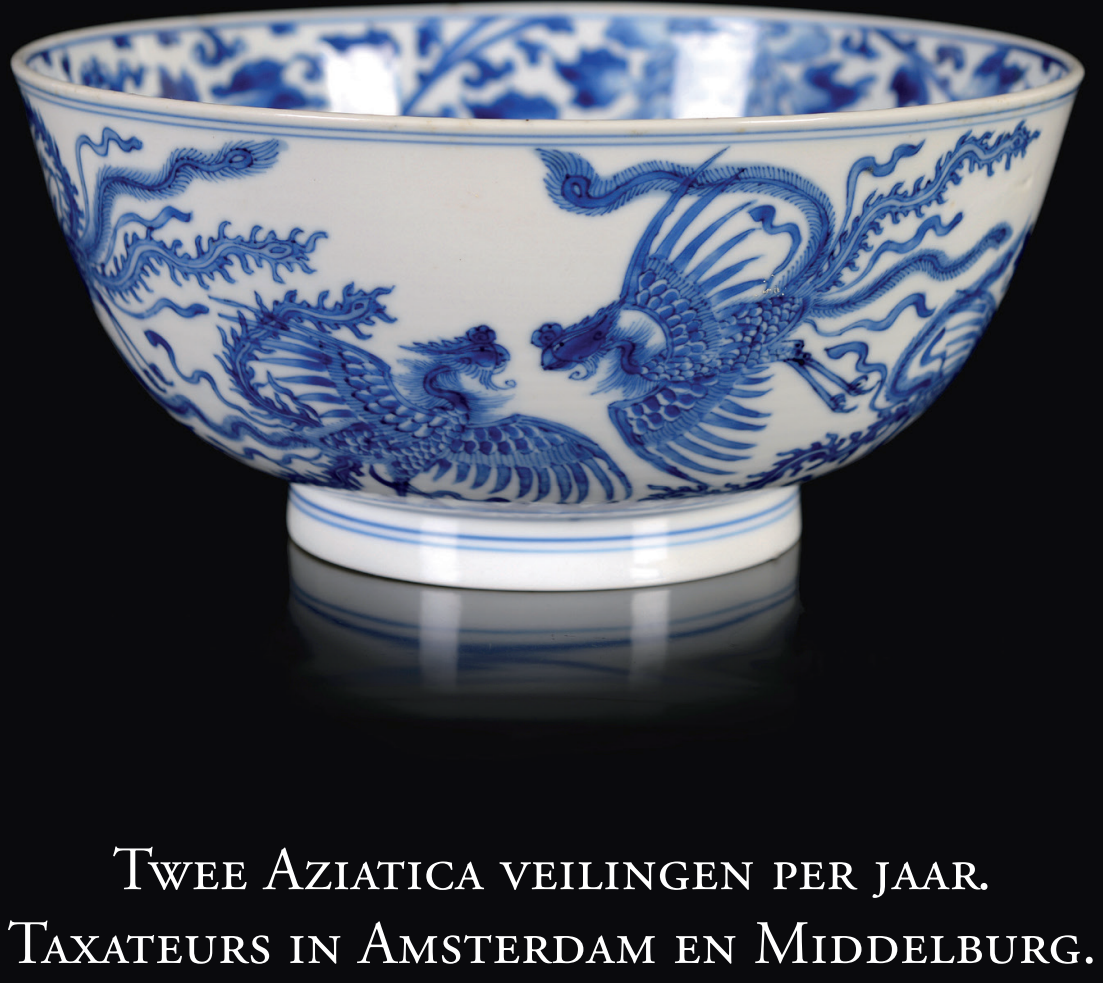

Herengracht 74 433 I PX Middelburg WWW.ZEEUWSVEILINGHUIS.NL | INFO@ZEEUWSVEILINGHUIS.NL 


\section{AstamANGALA}

OUDE KUNST UIT TIBET, NEPAL EN INDIA

KEIZERSGRACHT 574 • 1017 EM AMSTERDAM (SPIEGELKWARTIER)

TEL: 020-6234402・E-MAIL: ASTA@XS4ALL.NL・WWW.ASTAMANGALA.COM

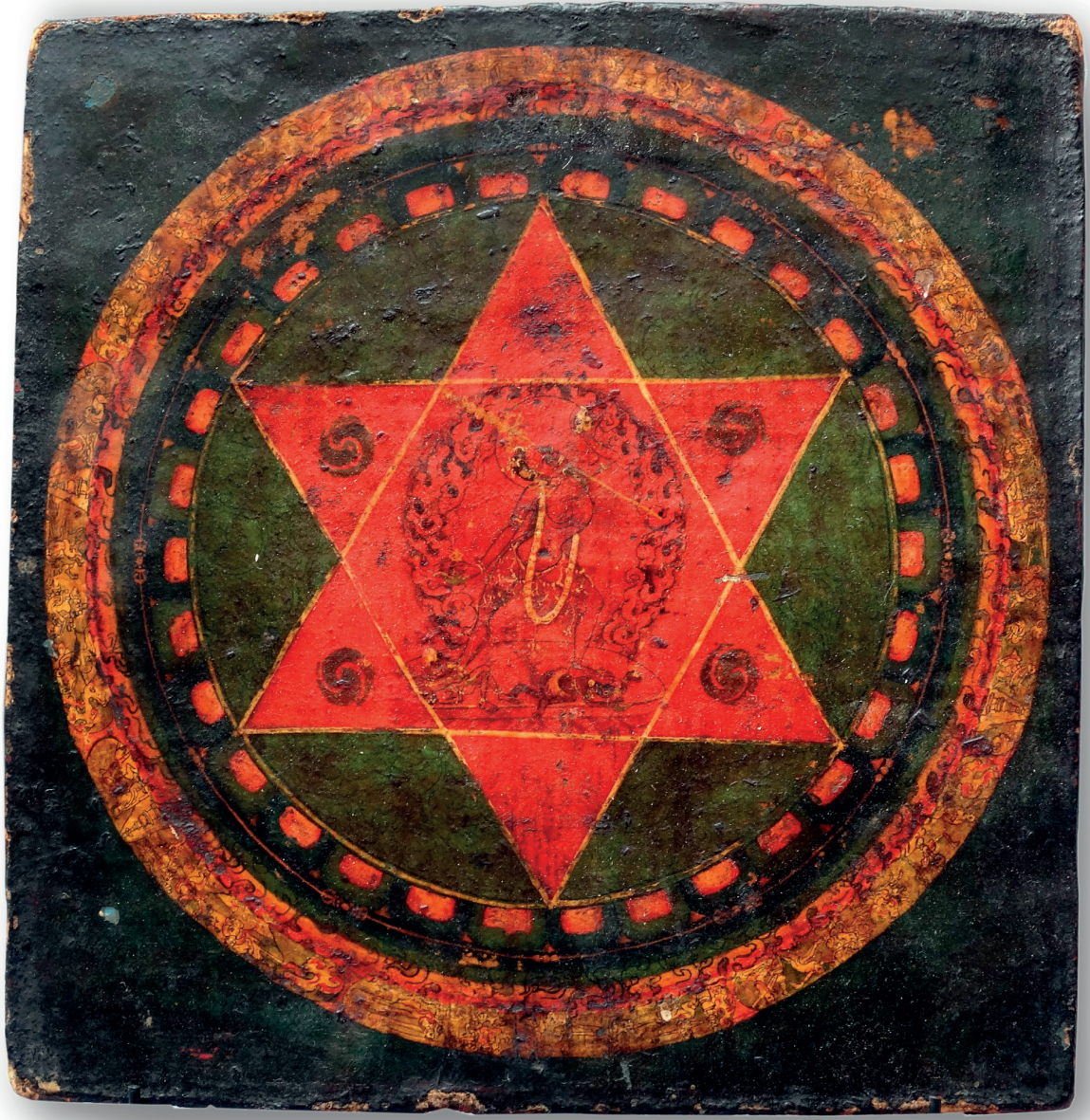

Mandala van Naro Dakini

verf op textiel en hout, Tibet, $17^{\text {de }}$ eeuw, afm.: $28 \times 28 \mathrm{~cm}$. 

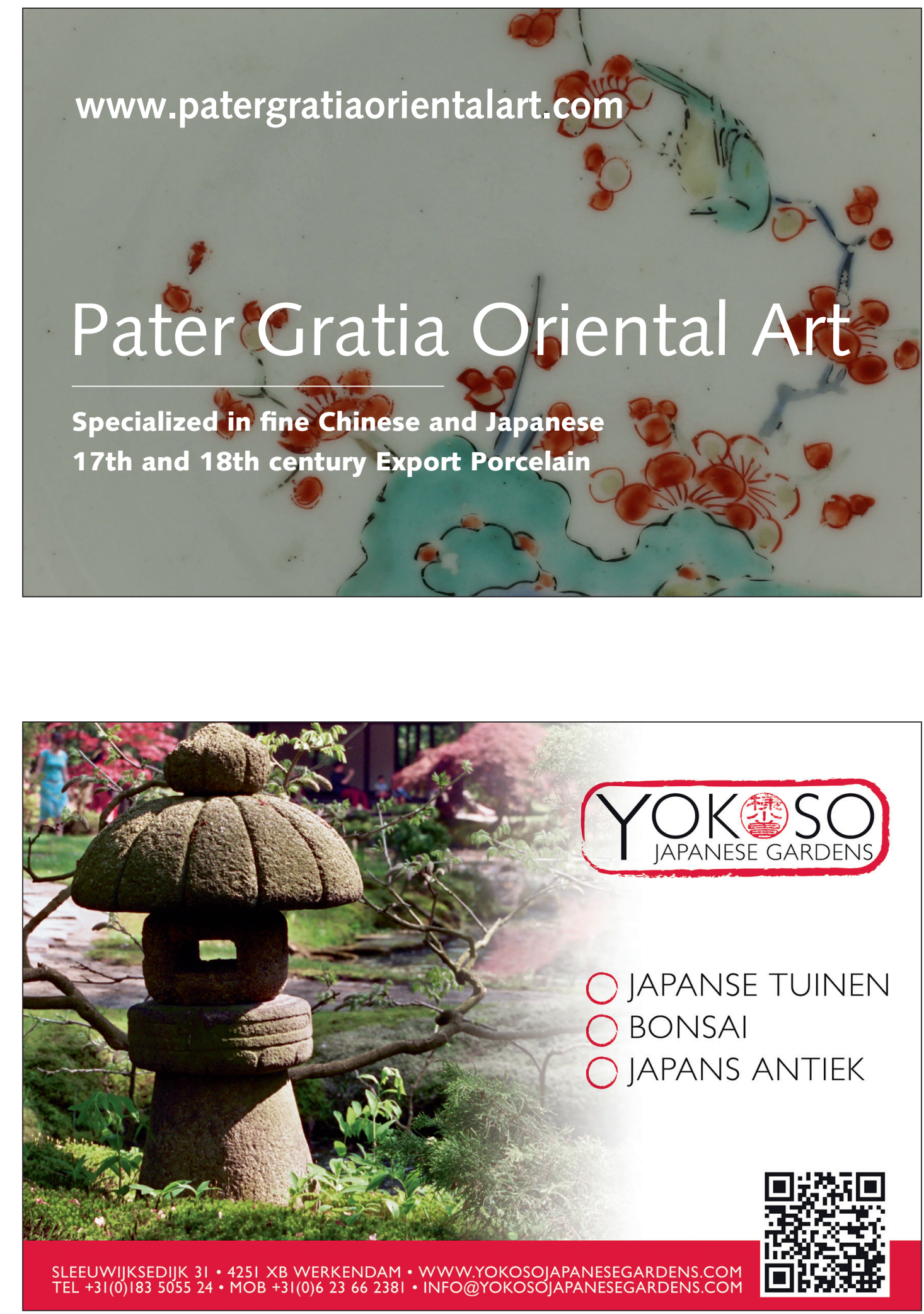


\section{Frides Laméris}

KUNST - EN ANTIEKHANDEL VOF

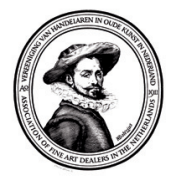

Nieuwe Spiegelstraat 55

IOI7 DD Amsterdam

Telefoon 020-6264066

info@frideslameris.nl

www. frideslameris.nl

glas - ceramiek

objets de collection

Famille verte bordje met in Chinese karakters het gedicht:

De ontluikende bloemen staan in hun betoverende pracht pal in de doordringende wind.

Bevallig en ontspannen rust Hare Hoogheid Mevrouw Yang in haar heerlijke bed.

In de afzondering van het bamboebos,

Zegen

Vroeg 18de eeuw, Ø 15,8 cm

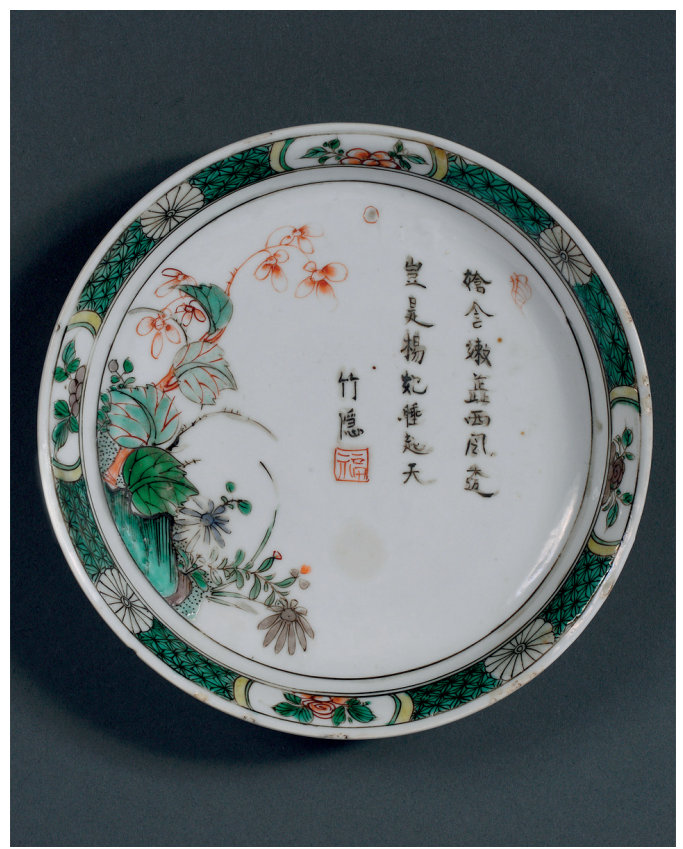

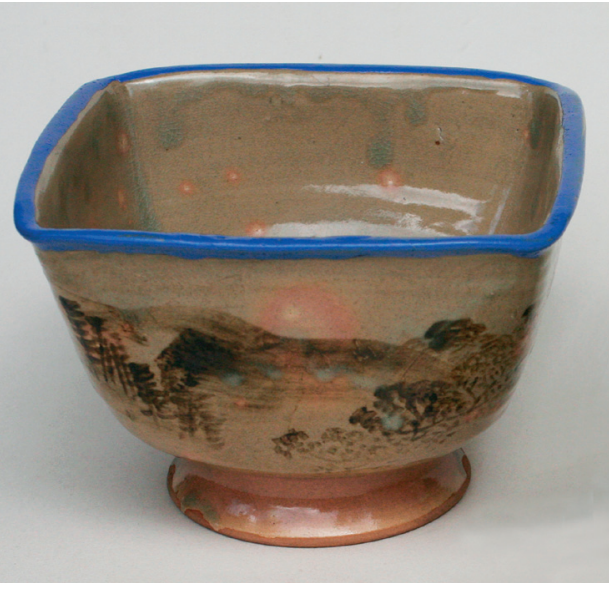

Matsumura Keibun (I779-1843)

Kiyomizu Rokubei II (c. 1797-1860) Landschap bij Kyoto

Vierkante Kyoyaki kom met onderglazuur schildering, $\square$ I5 X I0,3 cm. Gesigneerd Keibun en zegel Kiyo

PAN Amsterdam - 2I-29 november - Rai Amsterdam - Stand 78

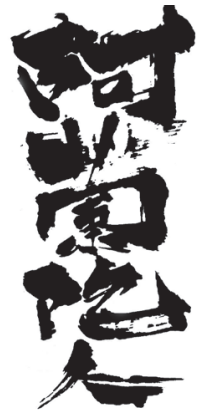

\section{ORANDA JIN}

Japanese paintings \& painters' pottery

Jon de Jong

Kalverstraat 28, $5223 \mathrm{AD}$ 's-Hertogenbosch tel: +31 (0)73-621 8951

e-mail: orandajin@home.nl

www.orandajin.com

(nieuwe update eerste week van de maand) 


\section{GUUS RÖELL FINE ART}

Tel.: 0653211649 | e-mail: g.roell@planet.nl | website: www.guusroell.com Tongersestraat 2, $6211 \mathrm{LN}$ Maastricht

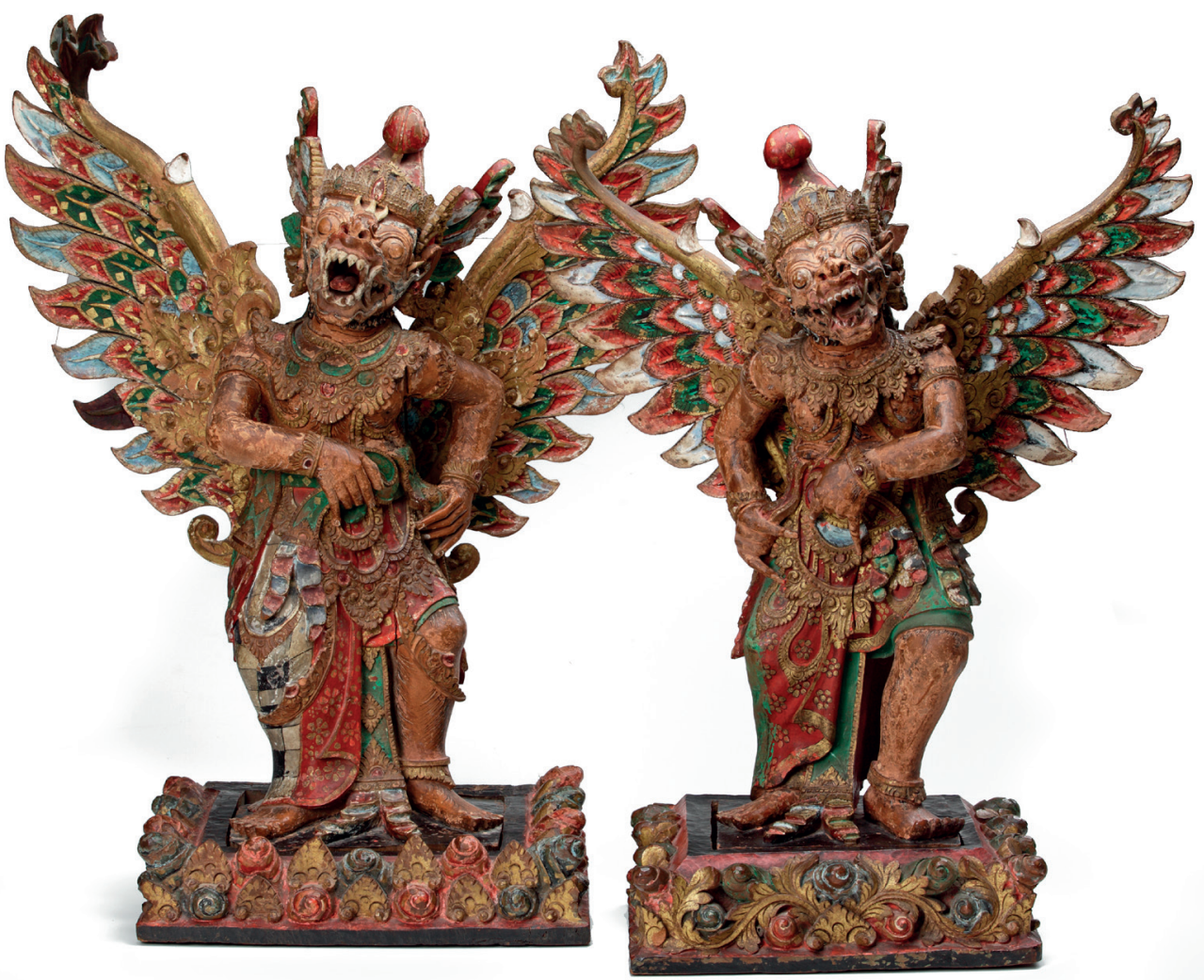

Twee polychroom en goud beschilderde houten beelden,

Noord Bali, Singaraja, I890-I920. Hoog, $78 \mathrm{~cm}$.

De twee beelden stellen de rode apen tweeling voor,

Sugriwa en Subali zoals ze op Bali worden genoemd. 


\section{KUNST EN ANTIEKVEILING 10-13 NOVEMBER}

Kijkdagen: vrijdag 6, zaterdag 7 en zondag 8 november van 10.00 tot 17.00 uur.

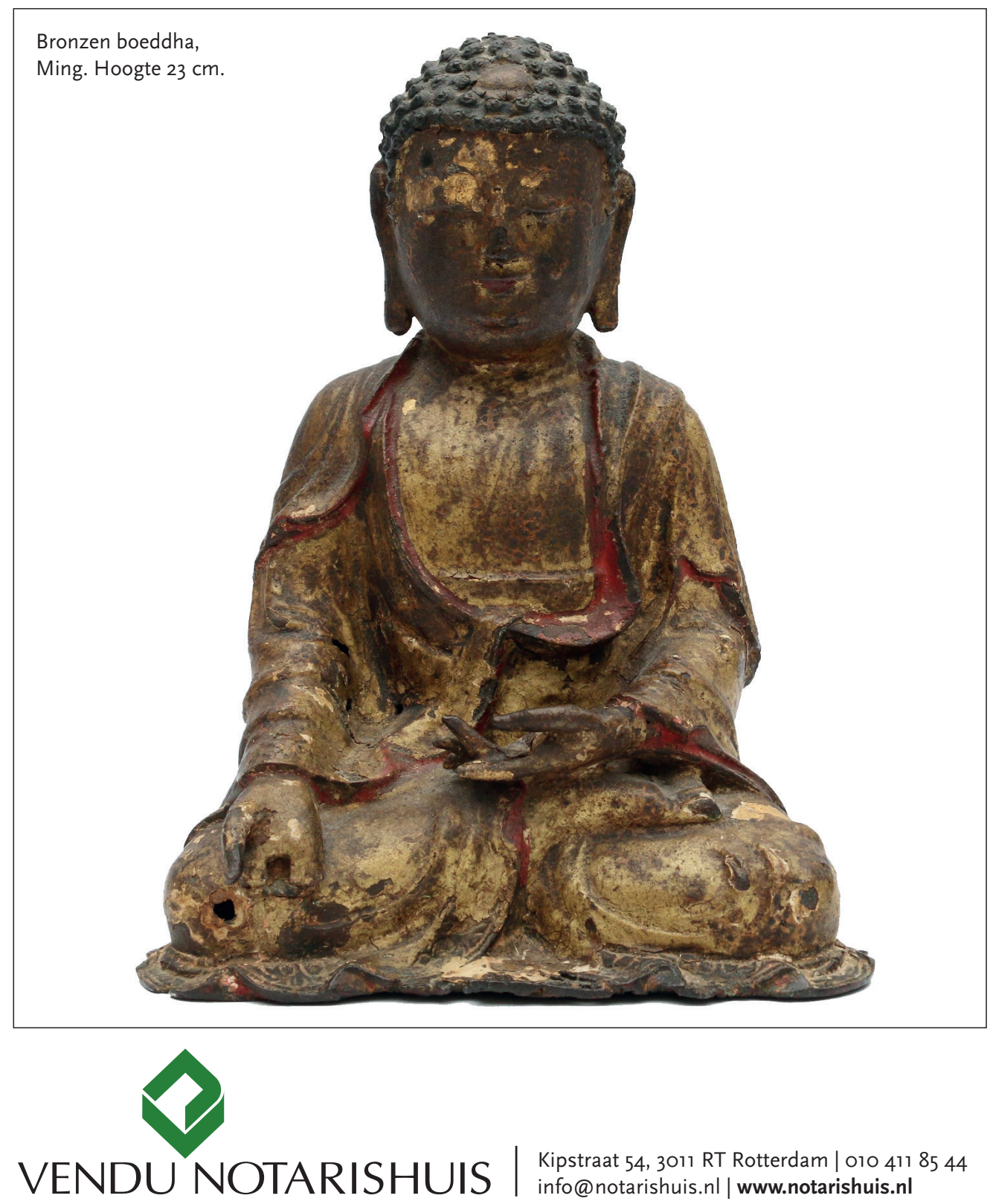




\section{LEMPERTZ}

1845

Aziatische kunst

incl. The Kolodotschko Collection of Netsuke IV

Veiling te Keulen 4-5 december 2015

Contact: +3I-(o)649318660vanpruissen@lempertz.com

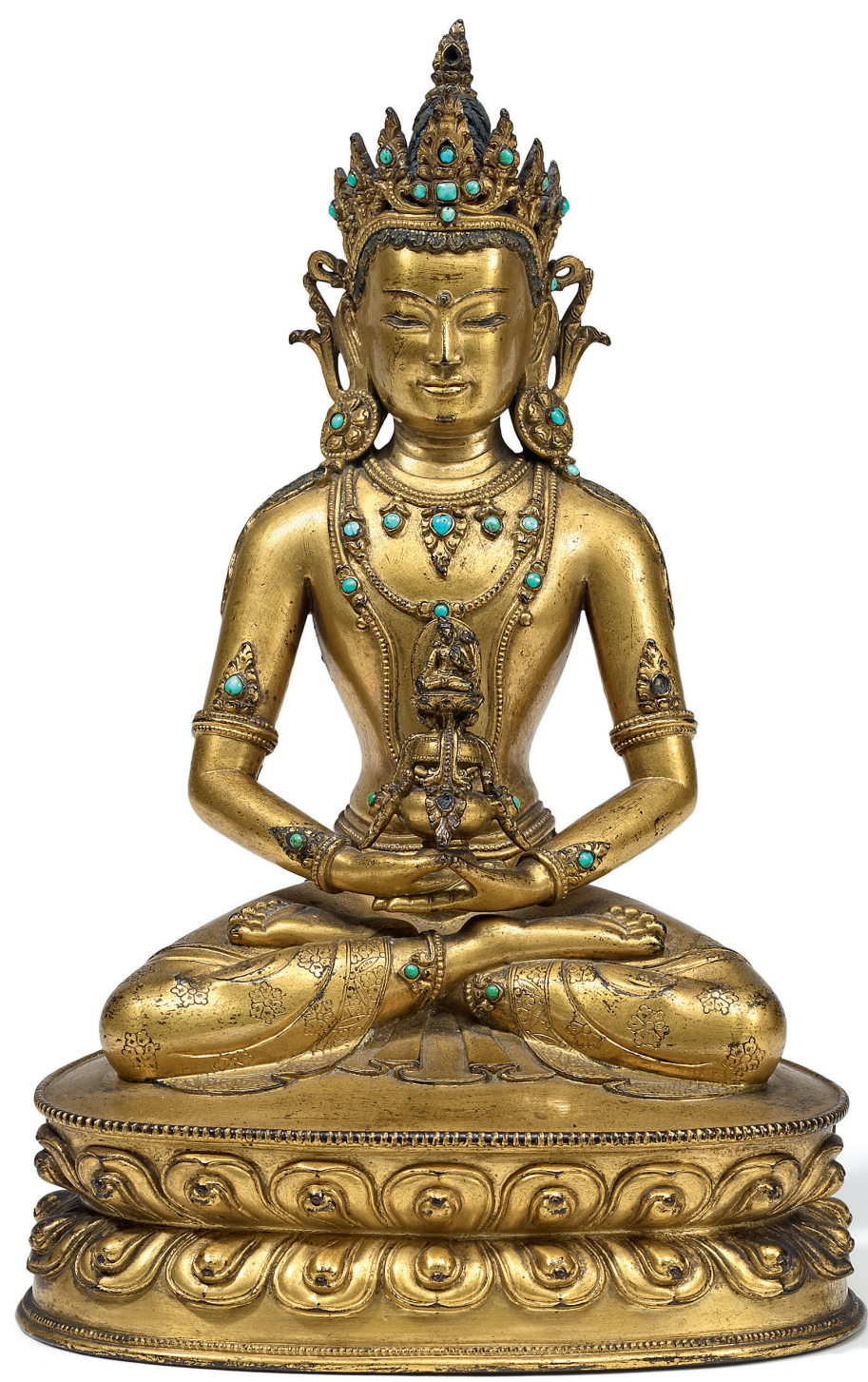

Buddha Amitayus. Tibet, I6e/I7e eeuw. Hoogte 2I cm 


\section{K A R M A - The Sculptural Heritage of Asia}

Exhibition 26 November - 31 December 2015 - Catalogue on request

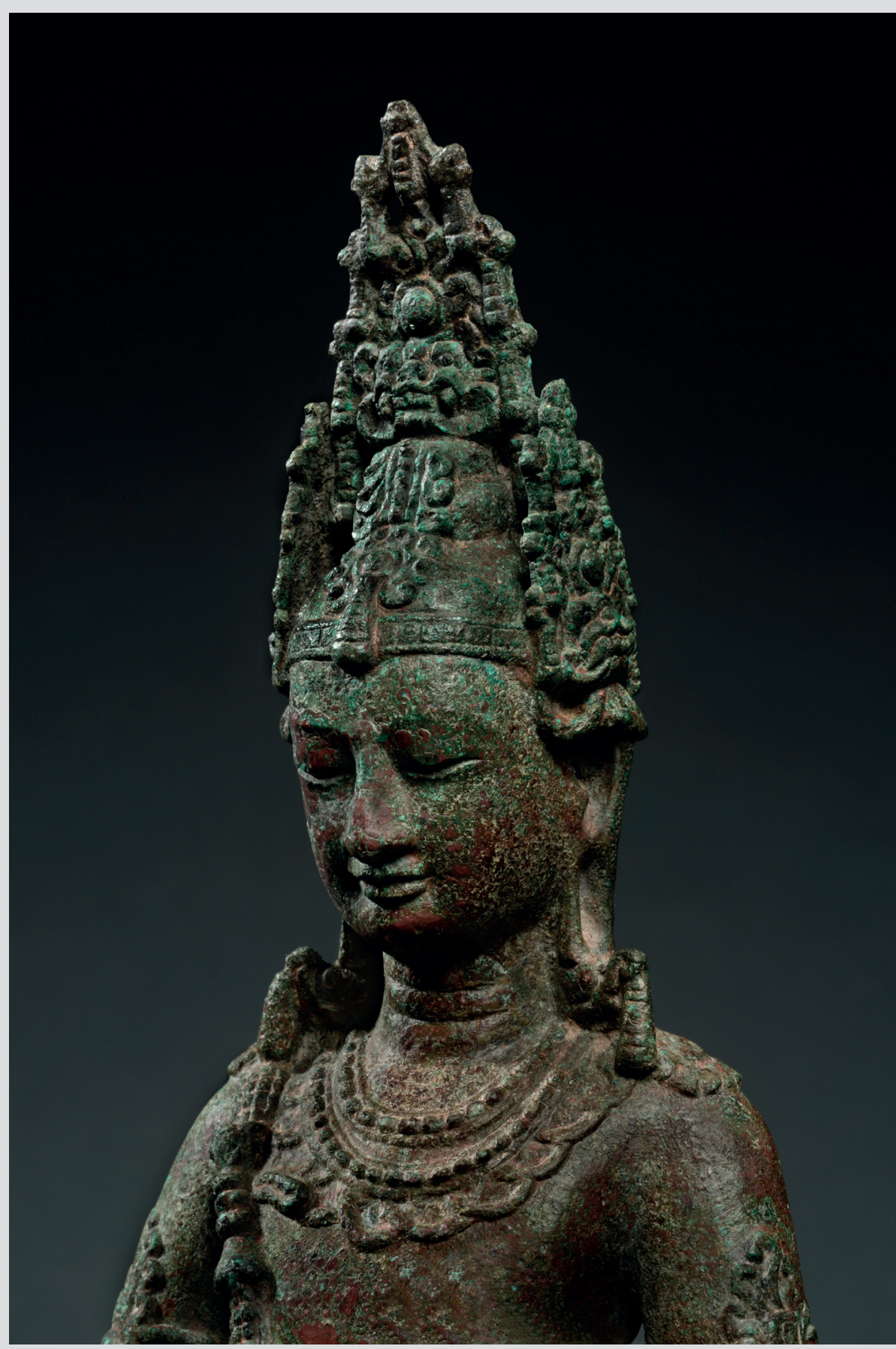

\section{MARCEL NIES ORIENTAL ART}

Lange Gasthuisstraat 282000 Antwerpen België marcelnies@skynet.be 


\section{Gallery China Art}

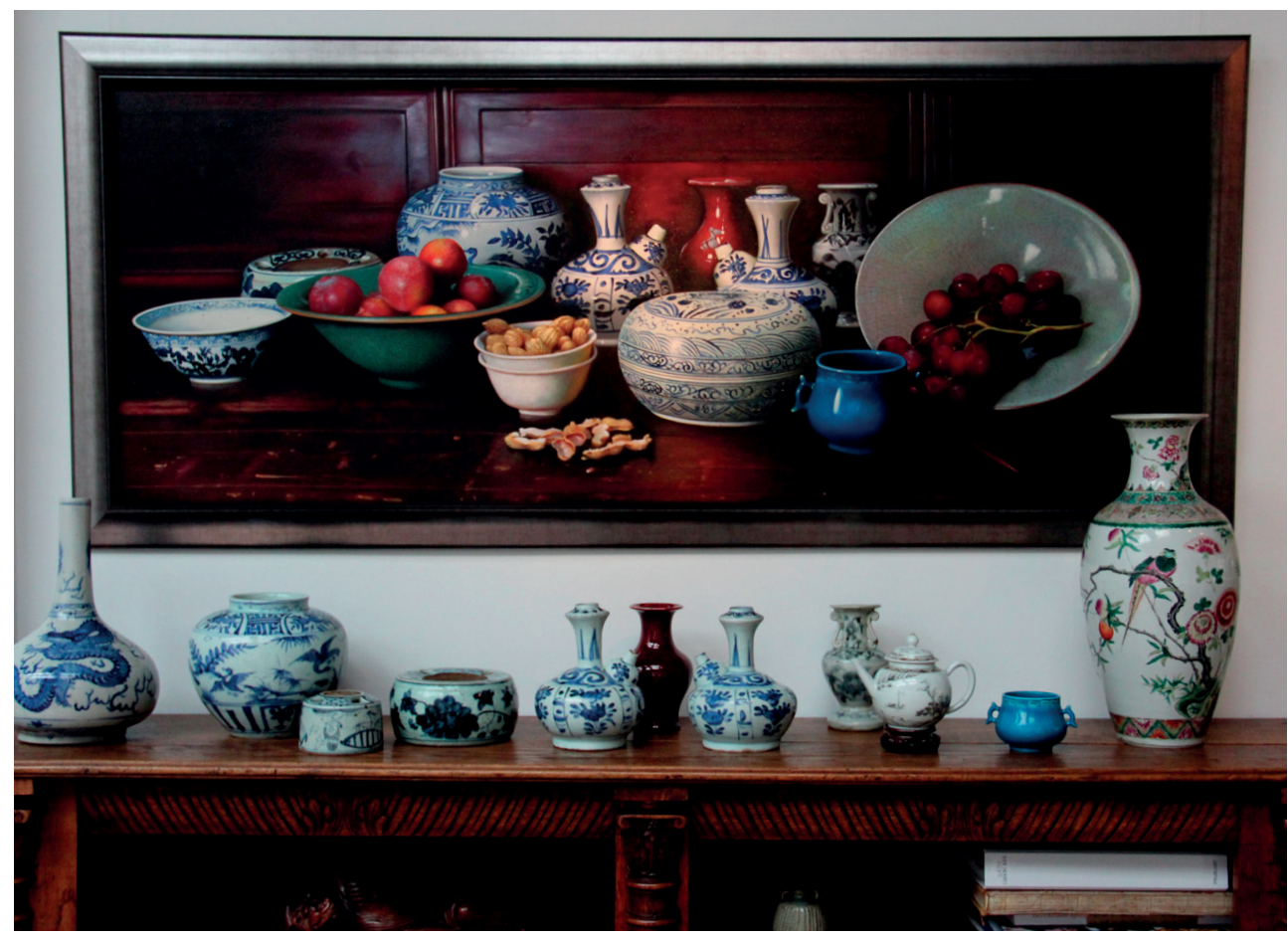

Chinese porseleinen uit de song ming qing dynasty

Mariniersweg 24 • 3011 NN Rotterdam

Tel: 010-229 3583

Openingstijden:

dinsdag t/m zaterdag van 11:00-17:00 uur en

zondag van 13:00-17:30 uur

mail: chinaartgallery@hotmail.com

www.gallery-china-art.nl 